\title{
Effect of PEAR1 Genetic Variants on 1-Year Outcomes in Chinese Patients with Acute Myocardial Infarction After Percutaneous Coronary Intervention
}

\author{
Yi Yao, Xiao-fang Tang, Chen He, Ying Song, Jing-jing Xu, Xian-min Meng, Bo Xu, Run-lin Gao and \\ Jin-qing Yuan
}

State Key Laboratory of Cardiovascular Disease, Fuwai Hospital, National Center for Cardiovascular Diseases, Chinese Academy of Medical Sciences and Peking Union Medical College, Beijing, People’s Republic of China

\begin{abstract}
Aims: Platelet endothelial aggregation receptor-1 (PEAR1) is a platelet transmembrane protein that plays an important role on platelet aggregation. The aim of this study was to investigate whether PEAR1 genetic variations are associated with 1-year outcomes in Chinese patients with acute myocardial infarction after percutaneous coronary intervention.

Methods: A total of 647 consecutive Chinese patients with acute myocardial infarction that underwent percutaneous coronary intervention and that were exposed to standard dual antiplatelet therapy with aspirin and clopidogrel were enrolled in this study. Six single nucleotide polymorphisms of PEAR1 were detected using the ligase detection reaction method. The follow-up period was 12 months.

Results: Overall, 66 (10.2\%) adverse ischemic events occurred. Multivariate Cox regression analysis showed that carriage of the PEAR1 rs56260937 minor allele was an independent predictor of revascularization events $(\mathrm{OR}=2.15,95 \% \mathrm{CI} 1.12-4.15, p=0.022)$ after adjusting for confounding factors. Conclusions: Genetic testing for PEAR1 variants can be helpful in predicting adverse ischemic events in Chinese patients with acute myocardial infarction after percutaneous coronary intervention.
\end{abstract}

Key words: Platelet endothelial aggregation receptor 1, Polymorphism, Outcome, Acute myocardial infarction, Percutaneous coronary intervention

\section{Introduction}

Platelet activation and aggregation plays a crucial role in the progression of acute thrombotic complications such as myocardial infarction and stent thrombosis. Dual antiplatelet therapy with aspirin and clopidogrel is a corner stone treatment for patients with acute coronary syndrome or those undergoing percutaneous coronary intervention $(\mathrm{PCI})^{1,2)}$. However, in clinical practice it has been found that some patients

Address for correspondence: Jin-qing Yuan, State Key Laboratory of Cardiovascular Disease, Fuwai Hospital, National Center for Cardiovascular Diseases, Chinese Academy of Medical Sciences and Peking Union Medical College, Beilishi Road No.167, Xicheng District, Beijing 100037, People’s Republic of China

E-mail: dr_jinqingyuan@sina.com

Received: January 22, 2017

Accepted for publication: October 16, 2017 are resistant to antiplatelet drugs and are more likely to experience adverse ischemic clinical events than oth$\mathrm{ers}^{3)}$. Genetic polymorphisms are known to contribute to such variations in drug response ${ }^{4,5)}$.

Platelet endothelial aggregation receptor-1 (PEAR1) is a platelet transmembrane protein which is activated by platelet-platelet contact and agonist stimulation. Once activated it sends signals to enhance and stabilize platelet thrombi in a manner dependent on functionality of GP IIb/III $\mathrm{a}^{6-8)}$. Some clinical trials have shown that genetic variation in PEAR1 is an important determinant of platelet reactivity during antiplatelet therapy ${ }^{9,10)}$. However, less is known about the relationship between PEAR1 gene polymorphisms and adverse outcomes, especially in Chinese patients. The present study aimed to assess the impact of PEAR1 single nucleotide polymorphisms (SNPs) on 1-year outcomes in Chinese patients with acute myocardial infarction (AMI) after PCI. 
Patients underwent percutaneous coronary intervention between

November 2011 and March 2013 ( $n=1483)$

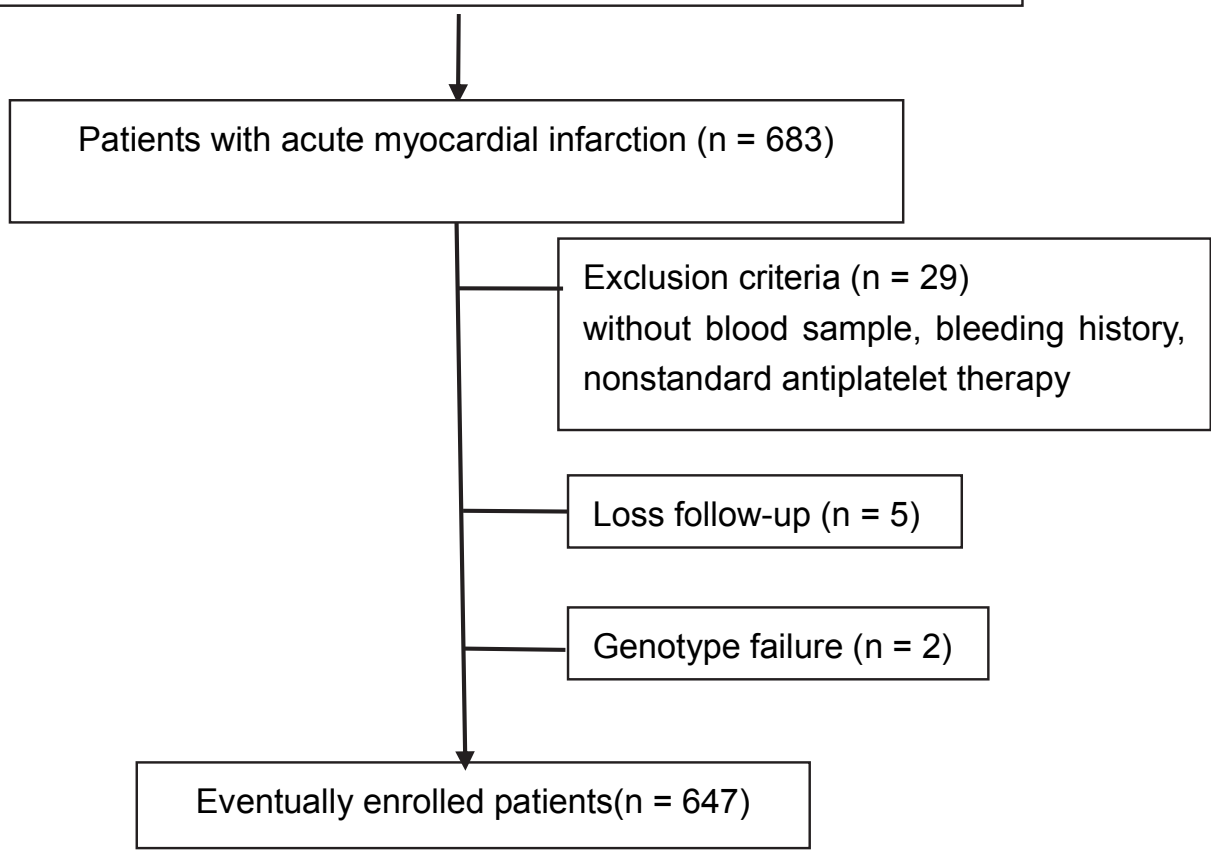

Fig. 1. Flow diagram describing the study design

\section{Methods}

\section{Study Population}

Patients with AMI admitted to the Fuwai Hospital with an uneventful PCI and who underwent standard dual antiplatelet therapy with aspirin and clopidogrel between November 2011 and March 2013 were enrolled in the study. The major exclusion criteria were: without blood sample, bleeding events within 1 year, usage of intensified antiplatelet agents, and other therapies than standard dual antiplatelet therapy with aspirin and clopidogrel. All patients received a $300 \mathrm{mg}$ loading dose (LD) of aspirin and a $300 \mathrm{mg}$ LD of clopidogrel before PCI, followed by a $100 \mathrm{mg}$ /day maintenance dose of aspirin for life and $75 \mathrm{mg} /$ day of clopidogrel for 1 year. The decision for PCI was based on the coronary angiography results and all interventions were conducted according to the European society of Cardiology (ESC) and the European Association for Cardio-Thoracic Surgery (EACTS) Guideline ${ }^{11)}$ on myocardial revascularization. The study was approved by the Fuwai Hospital Institutional Ethical Review Board. Written informed consent was obtained from all study participants. The study conformed to the principles outlined in the Declaration of Helsinki.

\section{Genetic Analysis}

PEAR1-SNPs that were associated with high platelet reactivity $(P$ values $<0.1)$ as measured by Thromboelastography in our previous study ${ }^{12)}$ were included in the analysis. Blood samples from a peripheral vein were obtained from each patient and stored in 4-mL ethylene diamine tetraacetic acid (EDTA) anticoagulated vacuum tubes. Genomic DNA was extracted from whole blood samples according to the salting-out protocol. All selected PEAR1-SNPs were genotyped using improved multiple ligase detection reaction (im LDR) with technical support from the Shanghai Genesky Biotechnology company. DNA sequencing techniques were used for quality control.

\section{Patient Follow-Up}

The incidences of all-cause death, cardiac death, myocardial infarction, revascularization, and stent thrombosis were recorded during a 1-year follow up. All patients were evaluated by clinic visit or by phone at 1 , 6, and 12 months. Death that could not be attributed to a non-cardiac etiology were considered cardiac death. Myocardial infarction (MI) was defined by the Third Universal Definition of Myocardial Infarction ${ }^{13)}$. Revascularization (RV) was defined as repeated revascularization for ischemic symptoms and events driven by PCI or surgery of any vessel. Stent thrombosis (ST) was 
Table 1. Clinical and laboratory characteristics of patients enrolled $(n=647)$

\begin{tabular}{|c|c|}
\hline Patients characteristics & Values \\
\hline Age (years), mean $\pm S D$ & $58.94 \pm 11.60$ \\
\hline Male, n (\%) & $518(80.1)$ \\
\hline Body mass index $\left(\mathrm{kg} / \mathrm{m}^{2}\right)$, mean $\pm \mathrm{SD}$ & $25.67 \pm 3.45$ \\
\hline \multicolumn{2}{|l|}{ Risk factor, $\mathrm{n}(\%)$} \\
\hline Current smoking & $294(45.4)$ \\
\hline Current alcohol drinking & $149(23.0)$ \\
\hline Diabetes mellitus & $199(30.8)$ \\
\hline Hypertension & $378(58.4)$ \\
\hline Hyperlipemia & $540(83.5)$ \\
\hline \multicolumn{2}{|l|}{ Laboratory measurements, mean $\pm S D$} \\
\hline Platelet count, $\left(\times 10^{9} / \mathrm{L}\right)$ & $210.20 \pm 62.96$ \\
\hline Hemoglobin, (g/L) & $138.03 \pm 17.06$ \\
\hline Serum creatinine, (umol/L) & $78.03 \pm 19.76$ \\
\hline Blood urea nitrogen, $(\mathrm{mmol} / \mathrm{L})$ & $6.15 \pm 2.25$ \\
\hline Low density lipoprotein, (mmol/L) & $2.69 \pm 0.90$ \\
\hline Left ventricular ejection fraction, (\%) & $55.13 \pm 8.43$ \\
\hline \multicolumn{2}{|l|}{ Type of acute myocardial infarction, n (\%) } \\
\hline ST-segment elevation myocardial infarction & $309(47.8)$ \\
\hline non-ST-segment elevation myocardial infarction & $338(52.2)$ \\
\hline \multicolumn{2}{|l|}{ Infarct-related artery, n (\%) } \\
\hline Left anterior descending & $364(56.26)$ \\
\hline Left circumflex & $132(20.40)$ \\
\hline Right coronary artery & $319(49.30)$ \\
\hline Left main & $32(4.95)$ \\
\hline Number of stent, mean \pm SD & $2.02 \pm 1.3$ \\
\hline Drug eluting stent, n (\%) & $602(93.04)$ \\
\hline Bare metal stent, $\mathrm{n}(\%)$ & $13(2.01)$ \\
\hline \multicolumn{2}{|l|}{ Concomitant medications, n (\%) } \\
\hline ACEI or ARB & $451(69.7)$ \\
\hline Beta-blocker & $578(89.3)$ \\
\hline Calcium channel blocker & $93(14.4)$ \\
\hline Nitrates & $597(92.3)$ \\
\hline Statin & $618(95.5)$ \\
\hline Proton pump inhibitor & $329(50.9)$ \\
\hline
\end{tabular}

SD: standard deviation; ACEI: angiotensin converting enzyme inhibitor; ARB: angiotensin receptor blocker

defined according to the Academic Research Consortium as definite, probable, or possible ${ }^{14}$. Composite ischemic events indicated the composite of cardiac death, MI, RV, and ST. All endpoints were adjudicated by 2 independent cardiologists, and disagreement was resolved by consensus.

\section{Statistical Analyses}

Continuous variables were presented as the mean \pm standard deviation (SD) and comparisons between groups of means were performed using the Student's $t$-test. Categorical variables were reported as counts (percentages) and Chi-square test $\left(\chi^{2}\right)$ was used to compare groups. Multivariate stepwise Cox regression analysis was conducted to identify independent risk PEAR1SNPs related to adverse ischemic events after adjusting for potential confounders which may affect outcomes including age, sex, BMI, DM, hypertension, hypercholesterolemia, smoking, alcohol, platelet count, hemoglobin, Scr, BUN, LDL cholesterol, LVEF, type of AMI, stent types, and number of infarct-related artery. The relationships between all enrolled SNPs and adverse events were analyzed in a recessive model. All statistical analyses were performed using SPSS ver. 20.0, and a 2 -tailed $P<0.05$ was considered to be indicative of statistical significance. 
Table 2. Effect of PEAR1 SNPs on clinical outcomes

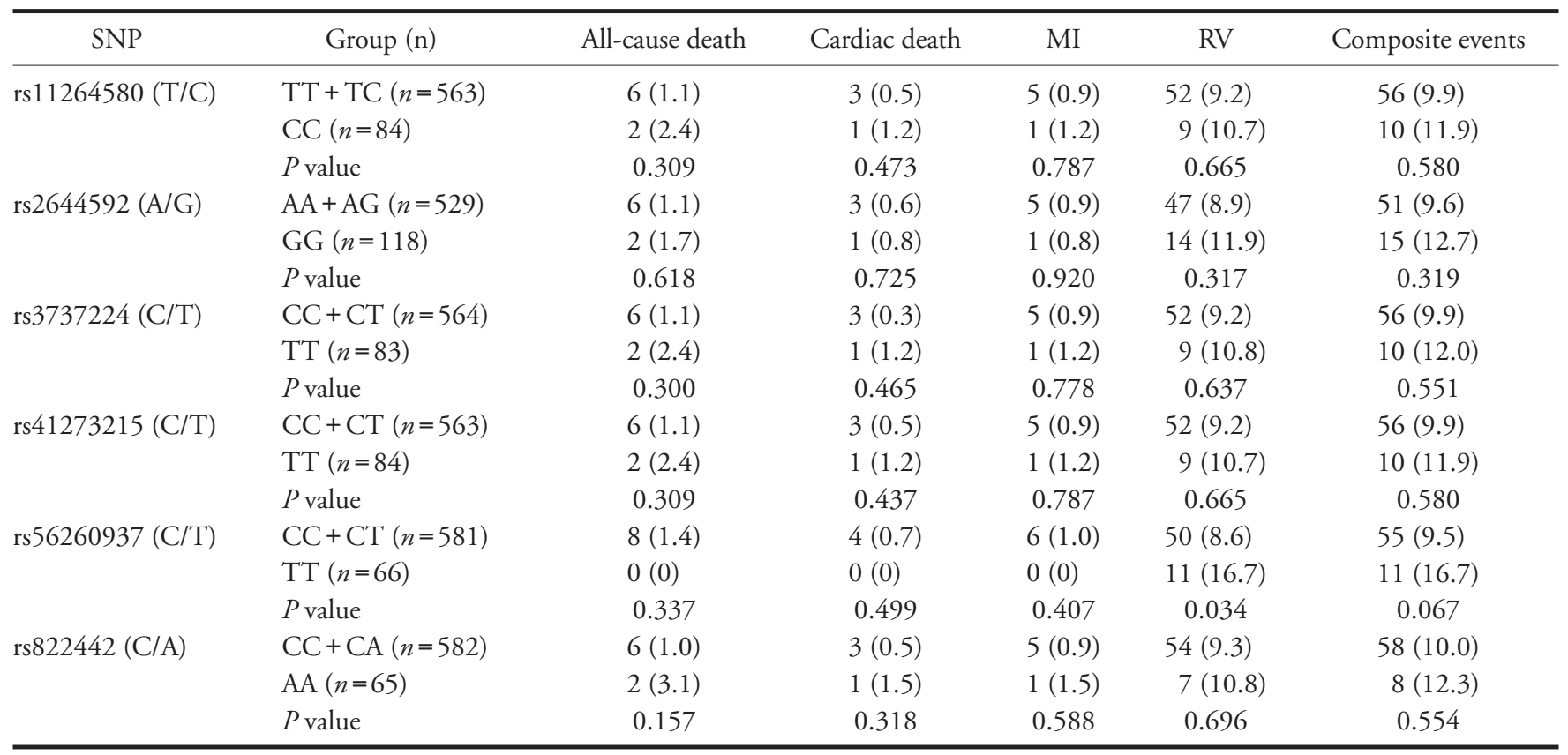

MI: myocardial infarction, RV: revascularization

\section{Results}

\section{Study Population}

A total of 647 AMI patients undergoing PCI and standard dual antiplatelet therapy were enrolled and available for genetic analysis. A flow chart describing the study design is shown in Fig. 1. The average age of patients was $58.94 \pm 11.60$ years and $518(80.06 \%)$ of patients were male. Clinical and laboratory characteristics of study subjects are shown in Table $\mathbf{1}$.

\section{PEAR1 SNPs and Clinical Outcomes}

At the 1-year follow-up, $66(10.2 \%)$ adverse ischemic events occurred: $8(1.2 \%)$ all-cause deaths, 4 (0.6\%) cardiac deaths, $6(0.9 \%)$ myocardial infarctions, and $61(9.4 \%)$ revascularizations. There were no ST events during 1-year follow-up. Six PEAR1-SNPs that were associated with high platelet reactivity from our previous study were enrolled in the present study for analysis: rs11264580 (T/C), rs2644592 (A/G), rs3737224 $(\mathrm{C} / \mathrm{T})$, rs41273215 (C/T), rs56260937 (C/T) and rs822442 (C/A ${ }^{12)}$. In the recessive model analysis, when compared to major allele, minor allele-T at rs56260937 showed a significant higher level of carrying frequency in the patients occurring revascularization events $(16.7 \%$ vs. $8.6 \%, P=0.034)$. The effects of PEAR1-SNPs on clinical outcomes are shown in Table 2. After adjusting for confounding factors including age, sex, BMI, DM, hypertension, hypercholesterolemia, smoking, alcohol, platelet count, hemoglobin, Scr, BUN, LDL cho- lesterol, LVEF, type of AMI, stent types and number of infarct-related arteries using stepwise Cox regression analysis, our results showed that rs56260937 was an independent predictor of revascularization events $(\mathrm{OR}=2.15,95 \%$ CI 1.12-4.15, $P=0.022)$.

\section{Discussion}

PEAR1 is a platelet transmembrane protein that is activated by platelet-to-platelet contact or agonist stimulation and that plays an important role in platelet function. A few foreign clinical trials have shown that genetic variations in PEAR1 result in high ontreatment platelet reactivity and adverse outcomes during antiplatelet therapy ${ }^{9}, 10,15,16$ ). To our knowledge, this is the first study to analyze the association between PEAR1-SNPs and outcomes in Chinese patients with AMI after PCI. Univariate and multivariate analysis both showed that minor allele-T at rs56260937 was significantly associated with higher incidences of revascularization events.

Kim et al. ${ }^{15)}$ sequenced the region on chromosome 1q23.1, including the entire PEAR1 gene, in 104 subjects to analyze the effect of PEAR1 variants on platelet function. Platelet function was tested using the PAP-4 Aggregometer after stimulating with collagen (2 $\mathrm{ug} / \mathrm{ml})$, adenosine diphosphate (10 $\mathrm{uM})$, or epinephrine $(2 \mathrm{uM})$. The results showed that rs56260937 significantly correlated with higher platelet reactivity for all 3 agonist phenotypes. Heightened platelet reactiv- 
ity is generally associated with a greater risk of ischemic events. Thus, this finding supports our results that show that rs 56260937 had a significant effect on revascularization events.

Apart from rs56260937, previous studies have reported other PEAR1-SNPs associated with adverse endpoints. Lewis et al. ${ }^{16)}$ showed that in patients treated with dual antiplatelet therapy (aspirin and clopidogrel) after percutaneous coronary intervention, minor A-allele carriers of rs12041331 were more likely to have composite adverse cardiovascular events compared with the major $\mathrm{G}$ allele; in aspirin-alone treated patients, rs12041331 A-allele carriers had a significantly increased risk of myocardial infarction. These findings further suggested that PERA1-SNPs were genetic contributors to interindividual different prognosis. Thus, PEAR1 genetic testing might be used to identify patients who carry PEAR1-SNPs that related to high platelet reactivity and so as to guide individualized treatment, for example, increasing drug dosage, using triple antiplatelet therapy or switching to a new antiplatelet agent like ticagrelor or prasugre, thus improve patient prognosis. The reason the SNP different from our findings might be due to differences in the ethnic groups of study populations.

The association between high platelet reactivity and adverse ischemic events has been shown in many studies ${ }^{17)}$. Mounting evidence suggests that genetic variants have a significant effect on platelet function ${ }^{18)}$. However, caution has been noted that high platelet reactivity associated with different genetic polymorphisms may have differential prognostic impact ${ }^{19,20)}$ : some SNPs related to high platelet reactivity are associated with higher incidence of adverse events ${ }^{19)}$, whereas other SNPs were not as reported by Voora D et $\mathrm{al}^{20)}$;, In our present study only minor allele-T at rs 56260937 showed association with higher incidence of ischemic events. The mechanism why some SNPs were associated with higher incidence of adverse events whereas other SNPs were not is currently unclear and remains to be investigated.

\section{Study Limitations}

The limitations of the current study are as follows: first, CYP2C19 polymorphisms, which are well known to affect platelet reactivity in patients treated with aspirin and clopidogrel, were not evaluated in the present study. Further studies are necessary to define the precise role of rs 56260937 after adjusting for CYP2C19 genotype. Second, our study was a single center retrospective study and only included one cohort. Thus, further multicenter prospective studies with larger sample sizes are required to consolidate our findings.

\section{Conclusions}

Genetic testing of PEAR1 variants can provide valuable information for predicting adverse ischemic events in Chinese patients with AMI-PCI Chinese.

\section{Acknowledgment}

This study was supported by grants from the National Natural Science Foundation of People's Republic of China (81470486) and National Key Research Project of The Thirteenth Five-Year Plan of People's Republic of China (2016YFC1301301).

\section{Conflicts of Interest}

None.

\section{References}

1) Showkathali R, Natarajan A. Antiplatelet and antithrombin strategies in acute coronary syndrome: state-of-the-art review[J]. Curr Cardiol Rev. 2012; 8: 239-249

2) Levine GN, Bates ER, Blankenship JC, Bailey SR, Bittl JA, Cercek B, Chambers CE, Ellis SG, Guyton RA, Hollenberg SM, Khot UN, Lange RA, Mauri L, Mehran R, Moussa ID, Mukherjee D, Nallamothu BK, Ting HH. 2011 ACCF/ AHA/ SCAI Guideline for Percutaneous Coronary Intervention: a report of the American College of Cardiology Foundation/American Heart Association Task Force on Practice Guidelines and the Society for Cardiovascular Angiography and Interventions[J]. Circulation. 2011; 124: e574-651

3) Wisman PP, Roest M, Asselbergs FW, de Groot PG, Moll FL, van der Graaf Y,de Borst GJ. Platelet-reactivity tests identify patients at risk of secondary cardiovascular events: a systematic review and meta-analysis[J]. J Thromb Haemost. 2014, 12: 736-747

4) Viviani Anselmi C, Briguori C, Roncarati R, Papa L, Visconti G, Focaccio A, De Micco F, Latronico MV, Pagnotta P, Condorelli G. Routine assessment of on-clopidogrel platelet reactivity and gene polymorphisms in predicting clinical outcome following drug-eluting stent implantation in patients with stable coronary artery disease[J]. JACC Cardiovasc Interv. 2013, 6: 1166-1175

5) Zhang JH, Wang J, Tang XF, Yao Y, Zhang Y, Ma YL, Xu B, Gao RL, Song L, Gao Z, Chen J, Wu Y, Yang YJ, Meng XM, Yuan JQ. Effect of platelet receptor gene polymorphisms on outcomes in ST-elevation myocardial infarction patients after percutaneous coronary intervention[J]. Platelets. 2016, 27: 75-79

6) Nanda N, Phillips D R. Novel targets for antithrombotic drug discovery[J]. Blood Cells Mol Dis. 2006, 36: 228231

7) Nanda N, Bao M, Lin H, Clauser K, Komuves L, Quertermous T, Conley PB, Phillips DR, Hart MJ. Platelet endothelial aggregation receptor 1 (PEAR1), a novel epidermal growth factor repeat-containing transmembrane 
receptor, participates in platelet contact-induced activation[J]. J Biol Chem. 2005, 280: 24680-24689

8) Kauskot A, Vandenbriele C, Louwette S, Freson K, Verhamme P , Hoylaerts MF. PEAR1 attenuates megakaryopoiesis via control of the PI3K/PTEN pathway[J]. Blood. 2013, 121: 5208-5217

9) Herrera-Galeano JE, Becker DM, Wilson AF, Yanek LR, Bray P, Vaidya D, Faraday N, Becker LC. A novel variant in the platelet endothelial aggregation receptor-1 gene is associated with increased platelet aggregability[J]. Arterioscler Thromb Vasc Biol. 2008, 28: 1484-1490

10) Wurtz M, Nissen PH, Grove E L, Kristensen SD, Hvas AM. Genetic Determinants of On-Aspirin Platelet Reactivity: Focus on the Influence of PEAR1[J]. PLoS One. 2014, 9: e111816

11) Task Force on Myocardial Revascularization of the European Society of Cardiology (ESC) and the European Association for Cardio-Thoracic Surgery (EACTS); European Association for Percutaneous Cardiovascular Interventions (EAPCI), Wijns W, Kolh P, Danchin N, Di Mario C, Falk V, Folliguet T, Garg S, Huber K, James S, Knuuti J, LopezSendon J, Marco J, Menicanti L, Ostojic M, Piepoli MF, Pirlet C, Pomar JL, Reifart N, Ribichini FL, Schalij MJ, Sergeant P, Serruys PW, Silber S, Sousa Uva M, Taggart D. Guidelines on myocardial revascularization[J]. Eur Heart J. 2010, 31: 2501-2555

12) Yao Y, Tang XF, Zhang JH, He C, Ma YL, Xu JJ, Song Y, Liu R, Meng XM, Song L, Chen J, Wang M, Xu B, Gao RL, Yuan JQ. Association of PEAR1 Genetic Variants With Platelet Reactivity in Response to Dual Antiplatelet Therapy With Aspirin and Clopidogrel in the Chinese Patient Population After Percutaneous Coronary Intervention[J]. Thrombosis Research. 2016, 141: 28-34

13) Thygesen K, Alpert JS, Jaffe AS, Simoons ML, Chaitman BR, White HD; Writing Group on the Joint ESC/ACCF/ AHA/WHF Task Force for the Universal Definition of Myocardial Infarction, Thygesen K,Alpert JS, White HD, Jaffe AS, Katus HA, Apple FS, Lindahl B, Morrow DA, Chaitman BA, Clemmensen PM, Johanson P, Hod H, Underwood R, Bax JJ, Bonow RO, Pinto F, Gibbons RJ, Fox KA, Atar D, Newby LK, Galvani M, Hamm CW, Uretsky BF, Steg PG, Wijns W, Bassand JP, Menasché P, Ravkilde J, Ohman EM, Antman EM, Wallentin LC, Armstrong PW, Simoons ML, Januzzi JL, Nieminen MS, Gheorghiade M, Filippatos G, Luepker RV, Fortmann SP, Rosamond WD, Levy D, Wood D, Smith SC, Hu D,
Lopez-Sendon JL, Robertson RM, Weaver D, Tendera M, Bove AA, Parkhomenko AN, Vasilieva EJ, Mendis S; ESC Committee for Practice Guidelines (CPG). Third universal definition of myocardial infarction[J]. Eur Heart J. 2012; 33: 2551-2567

14) Cutlip DE, Windecker S, Mehran R, Boam A, Cohen DJ, van Es GA, Steg PG, Morel MA, Mauri L, Vranckx P, McFadden E, Lansky A, Hamon M, Krucoff MW, Serruys PW; Academic Research Consortium. Clinical end points in coronary stent trials: a case for standardized definitions [J]. Circulation.2007; 115: 2344-2351

15) Kim Y, Suktitipat B, Yanek LR, Faraday N, Wilson AF, Becker DM, Becker LC, Mathias RA. Targeted deep resequencing identifies coding variants in the PEAR1 gene that play a role in platelet aggregation[J]. PLoS One. 2013, 8: e64179

16) Lewis JP, Ryan K, O'Connell JR, Horenstein RB, Damcott CM, Gibson Q, Pollin TI, Mitchell BD, Beitelshees AL, Pakzy R, Tanner K, Parsa A, Tantry US, Bliden KP, Post WS, Faraday N, Herzog W, Gong Y, Pepine CJ, Johnson JA, Gurbel PA, Shuldiner AR. Genetic variation in PEAR1 is associated with platelet aggregation and cardiovascular outcomes[J]. Circ Cardiovasc Genet. 2013, 6: 184192

17) Wisman PP, Roest M, Asselbergs FW, de Groot PG, Moll FL, van der Graaf Y, de Borst GJ. Platelet-reactivity tests identify patients at risk of secondary cardiovascular events: a systematic review and meta-analysis[J]. J Thromb Haemost. 2014, 12: 736-747

18) Geisler T, Schaeffeler E, Gawaz M, Schwab M.Genetic variation of platelet function and pharmacology: an update of current knowledge[J].Thromb Haemost. 2013 Nov; 110: 876-887

19) Tang XF, Wang J, Zhang JH, Meng XM, Xu B, Qiao SB, Wu YJ, Chen J, Wu Y, Chen JL, Gao RL, Yuan JQ, Yang YJ. Effect of the CYP2C19*2 and *3 genotypes, ABCB1 C3435T and PON1 Q192R alleles on the pharmacodynamics and adverse clinical events of clopidogrel in Chinese people after percutaneous coronary intervention[J]. Eur J Clin Pharmacol. 2013; 69: 1103-1112

20) Voora D, Horton J, Shah SH, Shaw LK, Newby LK. Polymorphisms associated with in vitro aspirin resistance are not associated with clinical outcomes in patients with coronary artery disease who report regular aspirin use.Am Heart J. 2011,162: 166-172 